\title{
Concreto convencional impermeabilizado pelo método de cristalização
}

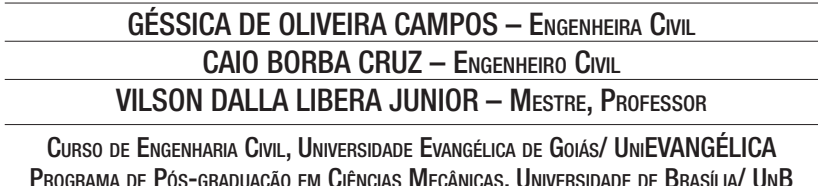

\section{RESUMO}

VISANDO SOLUCIONAR OS PROBLEMAS RELACIONADOS À ÁGUA, OS MÉTODOS DE IMPERMEABILIZAÇÃO DAS ESTRUTURAS SE TORNAM EXTREMAMENTE EFICAZES PARA REDUZIR OU ANULAR MANIFESTAÇÕES PATOLÓGICAS COMO UMIDADE, INFILTRAÇÃO E VAZAMENTOS EM RESERVATÓRIOS. NESTE CONTEXTO, ESTE ESTUdO TEVE COMO OBJETIVO ESTUDAR AS PROPRIEDADES DO CONCRETO CONVENCIONAL IMPERMEABILZADO PELOS MÉTODOS DE CRISTALIZAÇÃO, AVALIANDO SUAS PROPRIEDADES MECÂNICAS E DE ABSORÇÃO DE ÁGUA. FoRAM ESTUDADOS TRAÇOS DE CONCRETO FABRICADOS COM VARIAÇÕES DO ADITIVO DE IMPERMEABILIZAÇÃO CRISTALIZANTE EM
SUA COMPOSIÇÃOO. OS TRAÇOS FORAM AVALIADOS ATRAVÉS DE EXPERIMENTOS DE ABSORÇÃO D'ÁGUA, ABSORÇÃO POR CAPILARIDADE, RESISTÊNCIA À COMPRESSÃO E TRAÇÃO POR COMPRESSÃO DIAMETRAL. DE MODO GERAL, A APLICAÇÃO DO ADITIVO NO CONCRETO AUMENTOU A IMPERMEABILIDADE DAS AMOSTRAS E, CONSEQUENTEMENTE, ELEVOU A SUA RESISTÊNCIA MECÂNICA. OS PRINCIPAIS RESULTADOS INDICARAM A DOSAGEM ÓtIMA ENTRE 0,8\% E 0,4\%, SENDO A DOSAGEM DE 0,4\% RESPONSÁVEL POR UMA QUEDA EM ATÉ 68\% NA ABSORÇÃO TOTAL, INDICANDO A EFICIÊNCIA DA IMPERMEABILIZAÇÃO POR CRISTALIZAÇÃO.

Palavras-chave: impermeabilização, cristalização, concreto, propriedades mecânicas, absorção de água.

\section{INTRODUÇÃO}

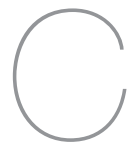

om o passar do tempo ocorre a deterioração das estruturas de concreto, visto que as mesmas possuem uma vida finita. Para alcançarem sua vida útil, as estruturas devem ser bem projetadas e submetidas a manutenções preventivas. Existem diversos fatores que geram deteriorações nas estruturas de concreto, sendo a água uma das principais responsáveis pela provocação de manifestações patológicas nas edificações.

Visando solucionar os problemas relacionados à água, os métodos de impermeabilização das estruturas têm se tornado extremamente eficazes para reduzir ou anular manifestações patológicas como umidade, infiltração e va- zamentos em reservatórios. Entretanto, devido à má aplicação e à escolha incorreta do produto impermeabilizante, o processo de impermeabilização pode perder sua efetividade, podendo acarretar prejuízos de caráter econômico, funcional, de desempenho, estéticos e estruturais, tendo potencial de gerar risco à segurança e à saúde dos usuários (CAPPELESSO et. al., 2019).

Quando se trata de prolongar a vida útil de uma estrutura de concreto, a impermeabilização é um processo de extrema importância, pois é o sistema responsável por selar ou vedar os materiais porosos e suas falhas, os quais resultam em umidade interna na edificação, aparecimento de manifestações patológicas, oxidação de armaduras, entre outros (ARAUJO \& SAVIATTO, 2018). Neste cenário, diversos sistemas e técnicas vêm sendo desenvolvidas para amenizar as agressões que ocasionam problemas de deterioração da edificação pela água na estrutura de concreto (SOARES, 2014).

A impermeabilização é definida por duas classes, sendo elas: rígidas e flexíveis. Os impermeabilizantes flexíveis são mais adequados para estruturas sujeitas a movimentação, como laje de cobertura, piscinas não enterradas e reservatórios elevados. Entre os impermeabilizantes flexíveis pode-se destacar a impermeabilização por cristalização, a qual é aplicada diretamente na massa do concreto, sendo considerada um sistema de proteção 
poroso (MUHAMMAD et. al., 2015). Neste sistema, o aditivo impermeabilizante é um composto químico à base de silicatos ativos que, ao entrar em contato com o cimento já hidratado ou no momento da hidratação, formam cristais que entopem os poros da estrutura, impedindo assim a penetração da água sob alta pressão e com efeito permanente. No caso de novas fissuras com dimensão de até $0,4 \mathrm{~mm}$, forma uma nova cristalização e consequente uma barreira impermeabilizante (OLIVEIRA et. al., 2019).

Apesar de apresentar um bom desempenho e elevar a durabilidade do concreto, o impermeabilizante por cristalização ainda é pouco estudado. Neste contexto, este trabalho teve como objetivo avaliar o método de impermeabilização por cristalização aplicado no concreto convencional, avaliando suas propriedades mecânicas, comparando suas propriedades físicas e verificando a eficiência do aditivo impermeabilizante.

\section{METODOLOGIA}

\section{I Materiais}

\section{I.I Cimento $\in$ ÁGUA}

O cimento Portland utilizado foi o composto por filer do tipo CP II-F-40 que apresenta resistência de $40 \mathrm{MPa}$ aos 28 dias. A água utilizada na dosagem do concreto foi proveniente do abastecimento público da cidade de Ceres $\mathrm{GO}$, que é fornecida pela companhia de saneamento de Goiás S/A - Saneago.

\section{I.2 Agregados}

O agregado fino utilizado foi a areia grossa, com granulometria de 0,2 mm a 0,6 mm. Os agregados graúdos usados na dosagem foram a brita 0 e brita 1 , as quais possuem a granulometria de $4,8 \mathrm{~mm}$ a $9,5 \mathrm{~mm}$ para a brita 0 , e $9,5 \mathrm{~mm}$ a $19 \mathrm{~mm}$ para a brita 1 , definidos pela NBR 7211 (ABNT, 2005).

\section{I.3 AdITIVo}

Foi utilizado neste estudo o aditivo impermeabilizante cristalizante, que aplicado ao concreto, apresenta características que visam reduzir a permeabilidade total. O aditivo é constituído por cimento Portland, areia de sílica fina tratada e outros compostos químicos ativos (PENETRON, 2013). O aditivo é fornecido em embalagens de sacos e baldes com $18 \mathrm{~kg}$. De acordo com o fabricante do produto, o consumo do aditivo deve ser, em média, 0,8\% em relação a massa de cimento da mistura e deve ser acrescentado no concreto no momento da sua produção.

\subsection{Programa experimental}

\subsection{DOSAGEM E PRODUCÃO DO CONCRETO}

As proporções de materiais empre-
> Tabela 1 - Proporções dos materiais em massa

\begin{tabular}{|cc|}
\hline Materiais & Proporções \\
\hline Cimento & 1 \\
\hline Areia natural & 1,36 \\
\hline Brita $\mathrm{n}^{\circ} 0$ & 1,08 \\
\hline${\text { Brita } \mathrm{n}^{\circ} 1}^{\circ}$ & 1,26 \\
\hline Aditivo polifuncional & $0,85 \%$ \\
\hline Aditivo cristalizante & $0,1 \% ; 0,4 \% ; 0,8 \%$ \\
\hline
\end{tabular}

gados foram baseadas em um traço de concreto de referência geralmente usado em edifícios fabricados na região de Goiás, onde apresenta um $\mathrm{f}_{\mathrm{ck}}$ de $25 \mathrm{MPa}$ aos 28 dias de cura. As proporções dos materiais utilizados são descritas na Tabela 1.

O concreto foi produzido em equipamento betoneira. Após produzido o concreto, foi realizado o ensaio de slump test, como demonstrado na Figura 1, para determinação da consistência, conforme exigido pela NBR NM 67 (ABNT, 1998).

Foram moldados corpos de prova de acordo com a NBR 5738 (ABNT, 2015), com 100 mm de diâmetro e
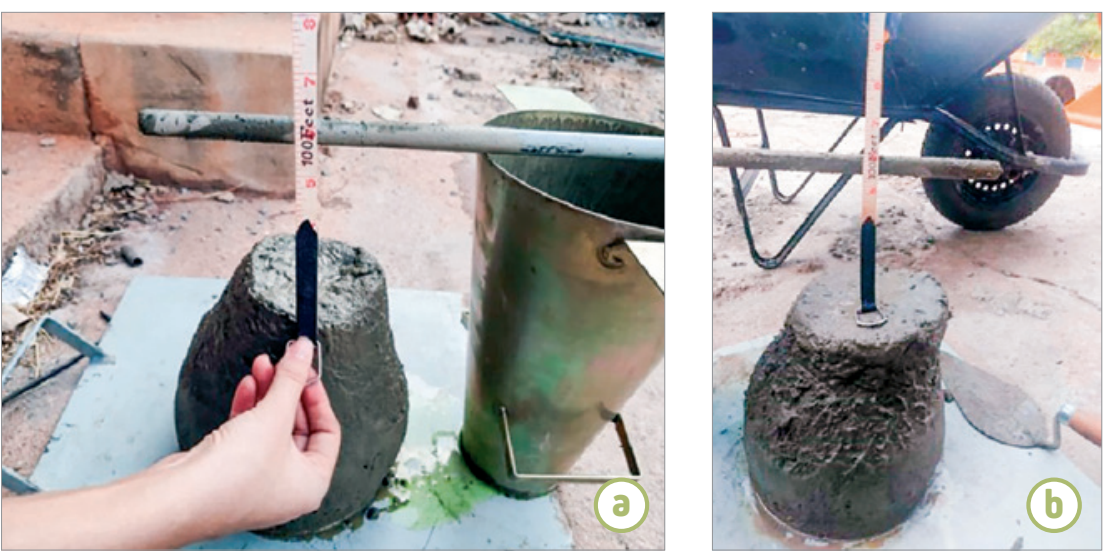

Figura 1

Ensaio de abatimento do concreto (slump test) 


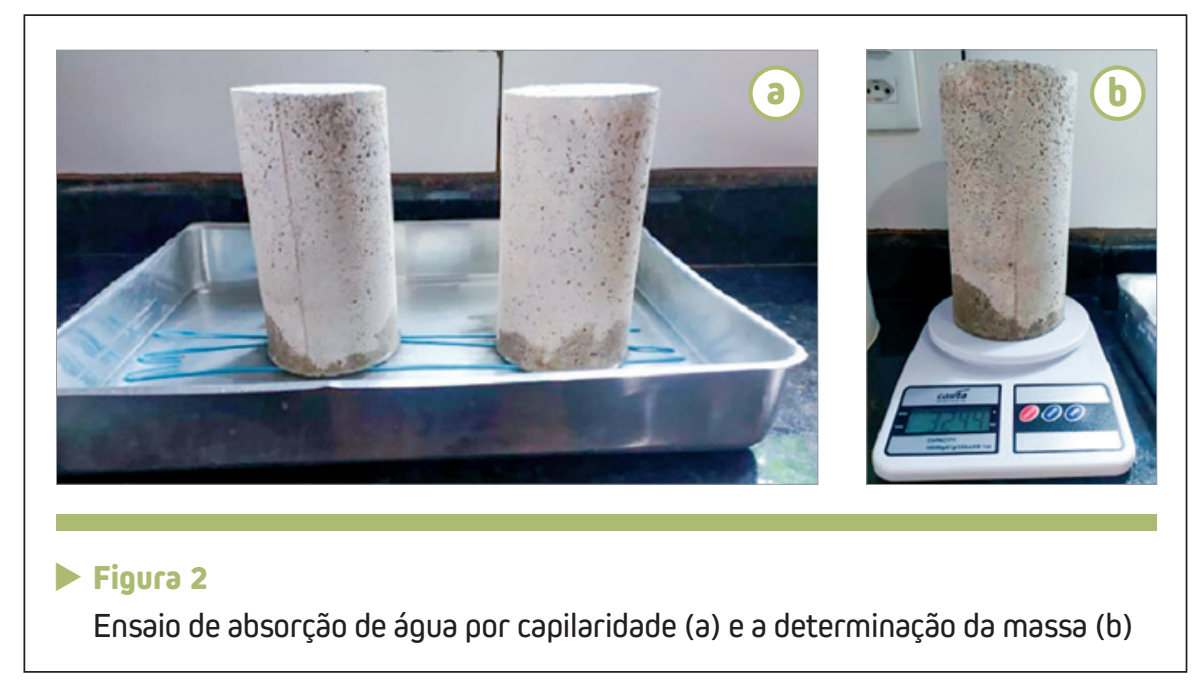

200 mm de altura. Após o período inicial de cura, os corpos de prova foram submersos na água, até completar 28 dias de cura.

\section{Z.ટ ENSAIOS MECÂNICOS}

O teste de resistência à compressão foi feito para determinar a capacidade do concreto de suportar esforços seguindo as recomendações da NBR 5739 (ABNT, 1993). O ensaio de tração por compressão diametral foi realizado seguindo a NBR 7222 (ABNT, 2011), a qual recomenda que o corpo de prova seja ensaiado deitado no meio dos pratos da prensa. Ambos os ensaios foram realizados em uma prensa manual digital modelo 100T (I-3001-C) da marca Contenco disponível no Laboratório de Materiais do curso de Engenharia Civil da UniEVANGÉLICA - Campus Ceres. Nos ensaios, foram analisados a carga de ruptura e o tipo de ruptura de quatro corpos de provas cilíndricos para cada traço de concreto.

\subsubsection{AbSorçÃo de ÁGUA TOtAL E POR CAPILARIDADE}

O ensaio de absorção total foi prova de cada traço foram colocados na estufa, com uma com temperatura constante de $(105 \pm 5){ }^{\circ} \mathrm{C}$ durante 24 horas. Após a secagem em estufa, os corpos de prova foram pesados e sua massa inicial foi medida. Posteriormente, os corpos de prova foram posicionados sobre um suporte em um recipiente com o nível d'água constante de $5 \pm 1 \mathrm{~mm}$ acima de sua face inferior conforme apresentado na Figura 2a. Durante o ensaio, a massa dos corpos de prova foi determinada com 3h, 6h, 24h, $48 \mathrm{~h}$ e $72 \mathrm{~h}$, medidas a partir do contato dos corpos de prova com a água (Figura 2b). Após este processo, os corpos de prova foram rompidos por compressão diametral, de acordo com a NBR 7222 (ABNT 2011), para que anotasse a distribuição d'água em seu interior e sua resistência mecânica.

\section{RESULTADOS E DISCUSSÃO}

\section{I Abatimento do concreto}

O ensaio de abatimento foi realizado para medir a consistência e verificar a trabalhabilidade do concreto para que o mesmo esteja apto a ser utilizado. Os resultados obtidos pelo ensaio de abatimento do concreto em estado fresco são apresentados na Tabela 2.

Foi possível observar na Tabela 2 que o traço do concreto convencional CC ficou menos denso em relação aos traços de concreto com a presença do
Tabela 2 - Abatimento do concreto (slump test)

\begin{tabular}{|ccc|}
\hline Traço & \multicolumn{1}{c}{ Descrição } & Slump $(\mathrm{mm})$ \\
\hline CC & Concreto convencional & 120 \\
\hline CAC 0,8 & Concreto com 0,8\% de aditivo cristalizante & 60 \\
\hline CAC 0,4 & Concreto com 0,4\% de aditivo cristalizante & 80 \\
\hline CAC 0,1 & Concreto com 0,1\% de aditivo cristalizante & 100 \\
\hline
\end{tabular}




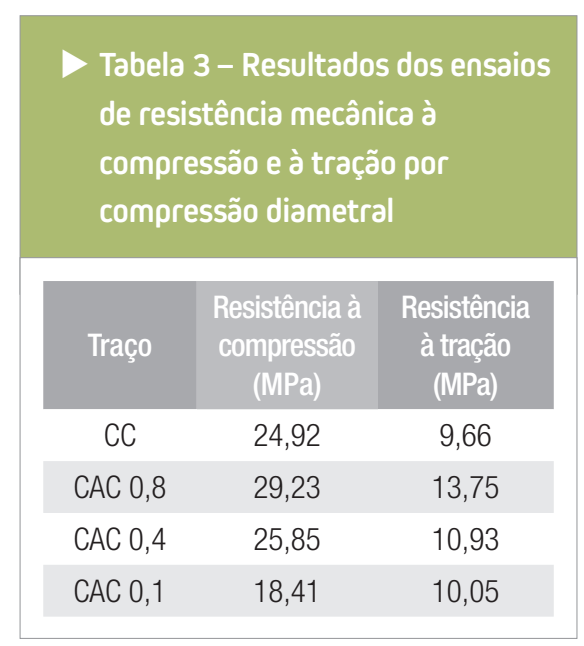

aditivo cristalizante. Conforme foi aumentado a quantidade do aditivo, ele diminuiu a fluidez, aumentando a coesão característica do traço, interferindo diretamente no slump test (OLIVEIRA et. al., 2019). Porém, os resultados se mantiveram conforme a norma NBR NM 67 (ABNT, 1998) recomenda.

\subsection{Resistência mecânica}

Na Tabela 3 são apresentados os resultados dos ensaios de resistência à compressão, que foram rompidos verticalmente e do ensaio de resistência à tração por compressão diametral. Nos resultados apresentados na tabela foi

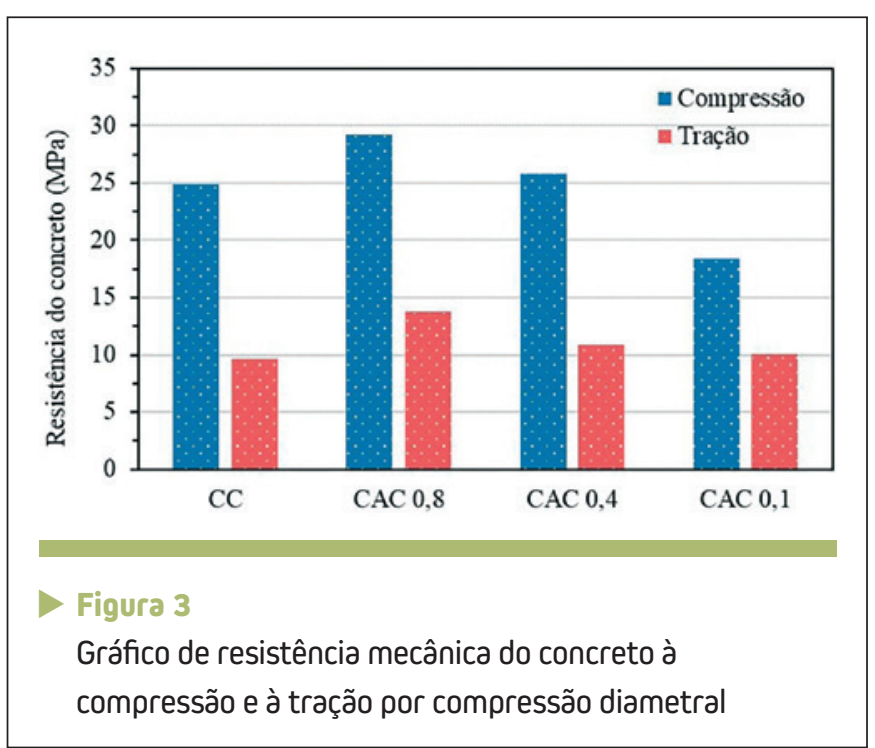

utilizada uma média dos valores da resistência de dois corpos de prova para cada traço analisado.

Nesses ensaios foi possível comprovar a eficácia da adição do aditivo impermeabilizante por cristalização, exceto no traço CAC 0,1, que por imprevistos durante a sua execução, houve a troca da areia utilizada e isto afetou a composição do traço. Os demais traços que utilizaram o aditivo cristalizante demonstraram um aumento significativo na resistência mecânica, principalmente no traço CAC 0,8, tanto a resistência à compressão quanto à tração, quando comparados com os corpos de prova de concreto convencional CC, sem a presença do aditivo cristalizante, conforme demonstrado na Tabela 3.

Através da análise da Figura 3, nota-se de forma mais clara que conforme foi aumentado a quantidade do aditivo cristalizante no traço do concreto, surtiu um efeito positivo na resistência mecânica dos corpos de prova, havendo um aumento de até 17,29\% de resistência à compressão, enquanto no ensaio de resistência à tração houve um aumento de $42,35 \%$ do traço CC para o CAC 0,8, isto ocorre, pois de acordo com o Instituto Brasileiro de Impermeabilização (2018) e Cappelesso et al., (2019), os cristalizantes aumentam a ligação interna entre os agregados através do fechamento dos poros e consequentemente altera a resistência mecânica.

O aumento na resistência mecâ-
Tabela 4 - Dados de absorção de água total dos traços estudados

\begin{tabular}{|c|c|}
\hline Traço & $\begin{array}{c}\text { Absorção de } \\
\text { água total } \\
(\%)\end{array}$ \\
\hline CC & 6,83 \\
\hline CAC 0,8 & 2,11 \\
\hline CAC 0,4 & 2,20 \\
\hline CAC 0,1 & 1,32 \\
\hline
\end{tabular}

nica dos traços com o aditivo cristalizante, notados na Figura 3, foram de acordo com o fabricante do produto, que consistia em um aumento de no mínimo 10\% em relação ao traço sem o aditivo (PENETRON, 2013).

\subsection{Absorção de água total $\epsilon$ por capilaridade}

Os resultados que foram obtidos através do ensaio de absorção de água total, realizados conforme a NBR 9778 (ABNT, 2005), estão apresentados na Tabela 4, mostrando, em porcentagem, a quantidade de água absorvida por cada traço.

Através do ensaio de absorção de água total, conforme seus resultados na Tabela 4, foi possível notar que no traço sem a presença do aditivo cristalizante CC ocorreu uma absorção de água discrepante, quando comparado com os demais traços com o aditivo impermeabilizante, exceto pelo traço CAC 0,1, que, por conta da alteração da areia, houve uma aplicação excessiva de água, resultando em uma absorção de água consideravelmente inferior que os traços anteriores.

A disparidade entre os traços com a presença do aditivo cristalizante, em relação ao concreto convencional, fica mais explícita quando observada na 
Figura 4, em que o CAC 0,8 e CAC 0,4 apresentaram resultados semelhantes e absorveram aproximadamente três vezes menos água que o traço convencional.

Os resultados obtidos sobre a absorção de água por capilaridade e apresentados na Tabela 5, foram realizados utilizando como base a norma NBR 9779 (ABNT, 1995). Estes resultados estão representados pela média dos valores encontrados por dois corpos de prova para cada traço.

Analisando a Tabela 5, pode-se notar que o traço CC iniciou as 3 primeiras horas já absorvendo bastante água, em relação aos traços restantes, finalizando com aproximadamente o dobro de absorção d'água, como observado na Figura 5, também apresentando uma resistência à tração inferior, devido à falta de impermeabilidade, pois a permeabilidade interfere diretamente na durabilidade e resistência da estrutura (ARAUJO \& SAVIATTO, 2018). Esta permeabilidade ocorre, pois através do fator água/cimento, uma quantidade elevada d'água presente na estrutura será evaporada, formando diversos poros vazios por todo o concreto, que irão permitir a infiltração d'água (GOMES et. al., 2003).

\begin{tabular}{|c|c|c|c|c|c|c|}
\hline \multirow{2}{*}{ Traço } & \multicolumn{5}{|c|}{ Absorção de água por capilaridade (\%) } & \multirow{2}{*}{$\begin{array}{c}\text { Resistência } \\
\text { à tração } \\
\text { (MPa) }\end{array}$} \\
\hline & $3 \mathrm{~h}$ & $6 \mathrm{~h}$ & $24 \mathrm{~h}$ & $48 \mathrm{~h}$ & $72 \mathrm{~h}$ & \\
\hline $\mathrm{CC}$ & 1,12 & 1,48 & 1,92 & 2,45 & 2,76 & 8,19 \\
\hline CAC 0,8 & 0,34 & 0,73 & 1,16 & 1,48 & 1,51 & 8,89 \\
\hline CAC 0,4 & 0,05 & 0,12 & 0,50 & 0,76 & 0,78 & 10,09 \\
\hline CAC 0,1 & 0,27 & 0,47 & 1,06 & 1,45 & 1,73 & 8,80 \\
\hline
\end{tabular}

Ao analisar a Figura 5, nota-se que o traço CAC 0,8 e CAC 0,4 se estabilizaram ao atingir as 48 e 72 horas do ensaio. Isso ocorreu devido à presença do aditivo cristalizante, que, ao entrar em contato com a água e com o hidróxido de cálcio, reage, formando os cristais insolúveis, selando e protegendo o concreto contra a penetração da água e outros líquidos. No traço convencional, a absorção de água continua crescente, portanto, o traço CC continua absorvendo mais água até que ele também se estabilize (BARBOSA, 2018; CAPPELESSO et al., 2019).

Considerando todos os traços, fica claro, na Figura 5, que o CAC 0,4 teve um destaque no ensaio de absorção de água por capilaridade, tendo uma ab- sorção d'água consideravelmente inferior e a resistência à tração superior que os demais traços. A Figura 6 mostra o interior dos corpos de prova de cada traço, após serem rompidos ao finalizar o ensaio de capilaridade. $\mathrm{Na}$ figura estão os traços CC (a), CAC 0,8 (b), CAC 0,4 (c), CAC 0,1 (d), respectivamente.

Analisado a Figura 6a, observa-se que o corpo de prova CC absorveu uma quantidade considerável de água durante as 72 horas do ensaio de capilaridade, sendo possível visualizar que a água atingiu mais da metade do corpo de prova. Enquanto os corpos de prova restantes, com a presença do aditivo cristalizante, finalizaram o ensaio de capilaridade com uma quantidade de água, visualmente,
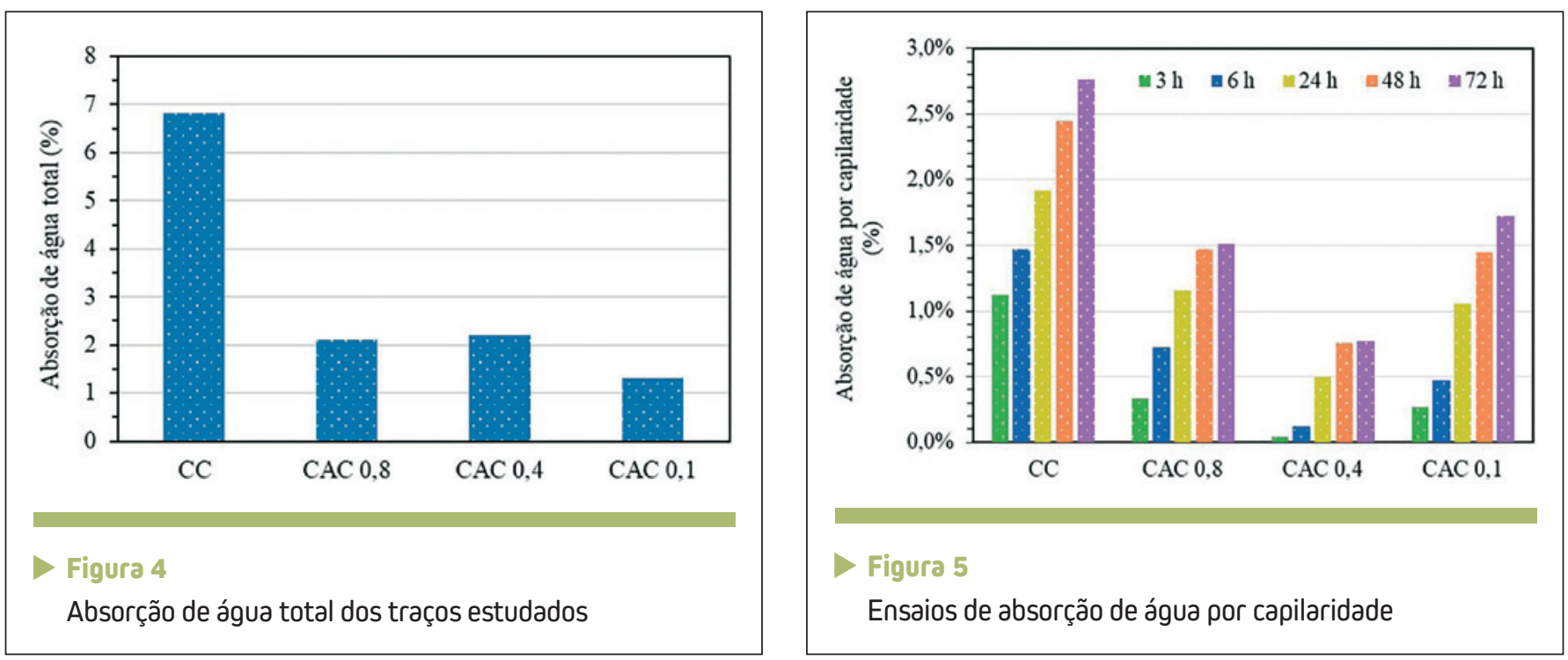

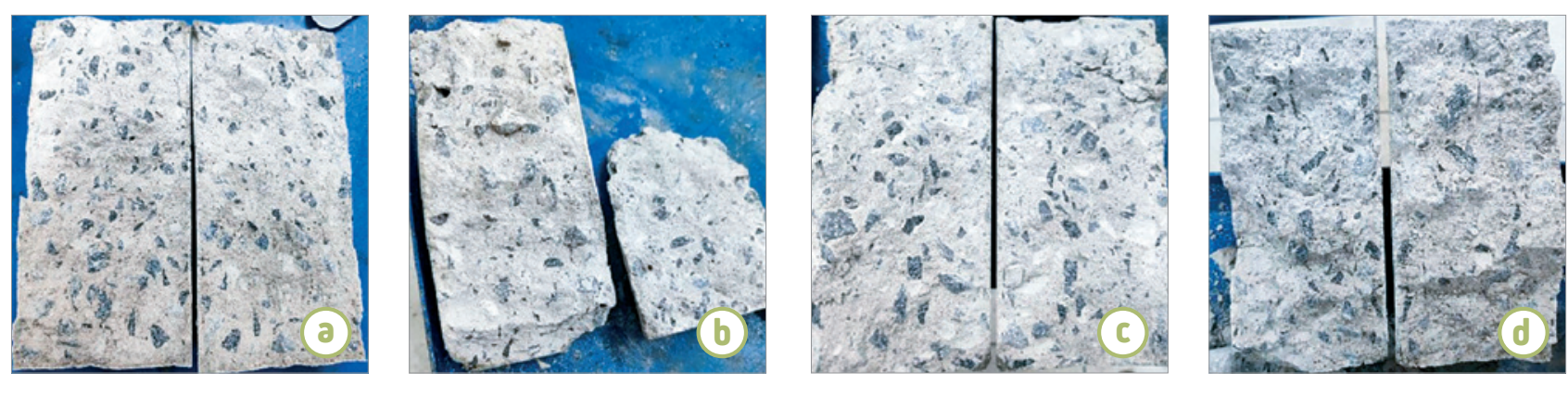

\section{Figura 6}

Corpos de prova após ruptura do ensaio de capilaridade

presente apenas na base dos corpos de prova, ficando impossibilitada de infiltrar mais profundamente na estrutura, por conta da formação dos cristais insolúveis, que impediram o avanço da água.

\section{CONCLUSÕES}

$\mathrm{O}$ estudo realizado indicou que $\mathrm{O}$ método de impermeabilização por cristalização é eficiente quando utilizado na dosagem correta. A análise da consistência dos concretos indicou que conforme foi aumentado a quantidade do aditivo, a fluidez foi diminuída e a coesão característica do traço aumentada, interferindo diretamente na trabalhabilidade.

Em relação a resistência, os traços com a presença do aditivo impermeabilizante por cristalização apresentaram resultados positivos que variaram de até 17,29\% para resistência à compressão e até 42,35\% para resistência à tração diametral em comparativo com o traço convencional, sendo o CAC 0,8 o traço com melhor desempenho mecânico. Analisando os resultados dos ensaios de absorção de água total e capilaridade, notou-se que o traço CAC 0,4 se destacou em ambos os ensaios, pois absorveu uma quantidade d'água inferior aos outros traços.

Portanto, a aplicação do aditivo no concreto possui eficiência considerável, tanto para a resistência mecânica quanto em relação à impermeabilidade da estrutura. Porém, em relação às dosagens do aditivo, é necessário que a mesma seja reavaliada entre $0,8 \%$ e $0,4 \%$, pois mesmo em quantidades inferiores, ainda apresentou um resultado positivo.

\section{DREFERÊNCIAS BIBLIOGRÁFICAS}

[1] ARAUJO, M. D; SAVIATTO, M. S. C. Estudo da influência de aditivo impermeabilizante em concreto. 2018. Trabalho de Conclusão de Curso apresentado ao Curso de Graduação em Engenharia Civil. Universidade do Sul de Santa Catarina, Palhoça. 2018.

[2] ABNT NBR 5738: Concreto — Procedimento para moldagem e cura de corpos de prova. Rio de Janeiro, 2015

[3] ABNT NBR 5739: Concreto — Ensaio de compressão de corpos-de-prova cilíndricos. Rio de Janeiro, 1993.

[4] ABNT NBR 67: Concreto — Determinação da consistência pelo abatimento do tronco de cone. Rio de Janeiro, 1998.

[5] _ ABNT NBR 7211: Concreto e argamassa - Determinação da resistência a tração por compressão diametral de corpos de prova cilíndricos. Rio de Janeiro, 2009.

[6] _ ABNT NBR 7222: Concreto e argamassa - Determinação da resistência a tração por compressão diametral de corpos de prova cilíndricos. Rio de Janeiro, 2011.

[7] _ ABNT NBR 9778: Argamassa e concreto endurecido - Determinação da absorção de água por imersão - Índice de vazios e massa específica - Método de ensaio. Rio de Janeiro, 2005.

[8] _ ABNT NBR 9779: Argamassa e concreto endurecidos — Determinação da absorção de água por capilaridade. Rio de Janeiro, 2012.

[9] BARBOSA, R. M. E. Patologia da impermeabilização de edificações: aspectos técnicos e metodológicos. 2018. Monografia apresentada ao Curso de Engenharia Civil. Universidade Federal do Rio de Janeiro, 2018.

[10] CAPPELLESSO, V. G; PETRY, N. S. et al., Use of crystalline waterproofing to reduce capillary porosity in concrete. 2016. J Build Rehabil. Disponível em: https://doi. org/10.1007/s41024-016-0012-7. Acesso em 21 set. 2019.

[11] GOMES, A. M. et al. Permeabilidade Do Concreto: Um estudo para a avaliação "in situ" usando instrumentos portáteis e técnicas tradicionais. 2003. Disponível em: <http:/l livrozilla.com/doc/592471/permeabilidade-do-concreto — um-estudo-para-aavalia\%C3\%A7\%C3\%A30> Acesso em: nov. 2020.

[12] IBI. Impermeabilização Rígida, ed. Pini. Disponível em: http://ibibrasil.org.br/wp-content/uploads/2018/01/Impermeabilizac\%CC\%A7a\%CC\%830-ri\%CC\%81gida.pdf. Acesso em: 25 mai. 2020.

[13] MUHAMMAD, N.; KEYVANFAR, A.; MAJID, M.; MIRZA, A. J. Waterproof performance of concrete: a critical review on implemented approaches. Construction and Buildings Material Vol. 101, p. 80-90. 2015.

[14] OLIVEIRA, L. N; BRITO, C. R, et al., Concrete curing analysis for high durability of structural concrete. 2019. Revista de Engenharia e Tecnologia para aplicações industriais Edição 17. Vol. 05. 2019.

[15] PENETRON, Ltda. PENETRON ADMIX: Ficha Técnica. 2013 Disponível em: http://www.penetron.com.br/downloads/fichas/ficha_tecnica_penetron_admix.pdf. Acesso em: 19 set. 2019.

[16] SOARES, F. F. A Importância do Projeto de Impermeabilização em Construção Civil. 2014. Monografia apresentada ao Curso de Engenharia Civil. Universidade Federal do Rio de Janeiro. 2014. 